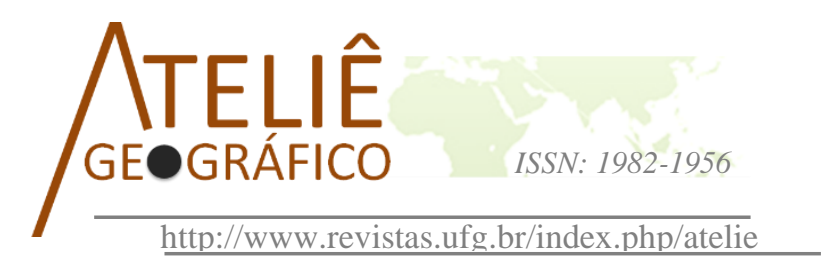

\title{
A evolução da periferia na conurbação Pelotas- Capão do Leão
}

\author{
The evolution of the periphery in the conurbation Pelotas - \\ Capão do Leão
}

\section{Evolución de la periferia en conurbación Pelotas-Capão do Leão}

\author{
Claure Morrone Parfitt \\ Universidade Federal de Pelotas \\ clauremparfitt@gmail.com \\ Betty Braga Gallo \\ Universidade Federal de Pelotas \\ bettybraga@yahoo.com.br \\ José Maria Filippini Alba \\ EMBRAPA-CPACT Pelotas \\ jose.filippini@gmail.com
}

\begin{abstract}
Resumo
A partir de uma discussão conceitual sobre periferia analisa-se o processo de produção de periferias em conurbação de cidade média, localizada no sul do Rio Grande do Sul.O objetivo desse trabalho consiste em investigar a expansão e a produção do espaço periférico que ocorreu na conurbação Pelotas- Capão do Leão R.S. no período de 1990 a 2011. Para o estudo foram utilizadas imagens LANDSAT 5 do Sensor ThematicMapper (TM).Os dados foram processados nos softwares Spring e Arc GIS. Além desse procedimento foram realizadas entrevistas nas prefeituras, pesquisa bibliográfica e IBGE. Os resultados indicam a produção de dois tipos de periferias na conurbação no período. Uma formada por assentamentos precários em Pelotas e Capão do Leão, e outra, constituída por loteamentos e condomínios fechados de médio e alto padrão em direção área com atrativos naturais. Constata-se que o crescimento das cidades está relacionado com a localização de um polo naval na vizinha cidade do Rio Grande, a fragmentação e difusão do espaço periférico, bem como, a formação de vazios urbanos no processo de produção do espaço.
\end{abstract}

Palavras-chave: Expansão urbana; Periferia; Conurbação; Brasil. 


\begin{abstract}
From a conceptual discussion on periphery, we analyzed the process of peripheralization in the conurbation of an average-sized city located in the south of the state of Rio Grande do Sul. We aimed to investigate the expansion and the production of peripheral space in the conurbation Pelotas-Capão do Leão, between 1990 and 2011. We used LANDSAT 5 images from the ThematicMapper (TM) sensor, and processed the data with softwares Spring and ArcGIS. The study also included interviews in the local city halls, bibliographical research and data from IBGE. Results indicate the production of two types of periphery in the conurbation analyzed, one formed by precarious settlements in Pelotas and Capão do Leão, and the other composed of medium and high standard subdivisions and gated residential areas around an area of natural attractions. We found that the growth of the cities is related to the location of a naval hub in the neighboring city of Rio Grande, the fragmentation and diffusion of the peripheral space and the formation of urban voids in the process of space production.
\end{abstract}

Keywords: Urban Expansion; Periphery; Conurbation; Brazil.

\title{
Resumen
}

A partir de una discusión conceptual sobre periferia se analiza el proceso de producción de periferias en conurbación de ciudad media localizada en el sur de Brasil.El objetivo de ese trabajo consiste en investigar la expansión y la produción del espacio periferico que ocurrió en la conurbación Pelotas- Capão do León RS en el período de 1990 a 2011. Para el estudio se utilizaron imágenes LANDSAT 5 del sensor ThematicMapper (TM). Los datos se procesaron en el software Spring y Arc GIS. Se realizaron tambiem entrevistas en las alcaldías, investigación bibliográfica e IBGE. Los resultados indican la producción de dos tipos de periferias en el período. Una formada por asentamientos precarios y otra constituida por lotes y condominios cerrados de medio y alto padrón en dirección área con atractivos naturales. Se constata que el crecimiento de las ciudades está relacionado con la ubicación de un polo naval en la vecina ciudad del Río Grande, la fragmentación y difusión del espacio periférico, así como la formación de vacíos urbanos en el proceso de producción del espacio.

Palabras clave: Expansión urbana; Periferia; Conurbación; Brasil.

\section{Introdução}

No espaço urbano brasileiro, a expansão da periferia, a partir das três últimas décadas do século XX, até os dias atuais, em grandes cidades e, também nas de porte médio está relacionada à intensa urbanização, que provoca no país a formação de loteamentos regulares, (que seguem a Lei Federal 6766/79), condomínios exclusivos, específicos para a população com maior poder aquisitivo; pelos loteamentos irregulares ou clandestinos, bem como, o surgimento de favelas; áreas precárias de habitação desprovidas de infraestrutura, normalmente em invasões.

A periferia é um espaço em transformação. Usualmente tem sido considerada como aquela área da cidade, que em termos de localização situa-se nos arredores do espaço urbano. Não se constitui em uma faixa circular homogênea, tanto em termos naturais como sociais (CORREA, 1989). 
Nas cidades brasileiras observa-se a materialização desse espaço nos seguintes termos: de um lado tem-se a periferia das pessoas mais abastadas provida de infraestrutura e amenidades, muitas vezes localizada cerca a belezas naturais, como as orlas, e a periferia onde vivem os mais pobres, subequipada e longínqua, onde seus habitantes detêm as piores localizações ficando a mercê de precários meios de transporte (CORREA, 1989)

A expansão periférica relacionada com o desenvolvimento capitalista no Brasil, representa a acumulação desigual de capital, refletida nas condições de moradia, fator determinante da segregação espacial urbana (CARLOS, 2008).

Nesse sentido, a expansão das cidades médias tem revelado a expansão das desigualdades e a exclusão social (CARVALHO, 2003). Aquelas com população entre 100 mil e 500 mil habitantes, que cresceram a taxas maiores do que as metrópoles, nos anos 80 e 90 (4,8\% contra 1,3\%) (MARICATO, 2000).

O crescimento da população urbana, durante as últimas décadas em cidades médias, tem sido acompanhado por um aumento na demanda por áreas urbanas, fato que proporcionou a ocupação de suas áreas periféricas. Esses processos acarretam espraiamento das cidades caracterizado pela periferização, fragmentação e dispersão (SANTOS, 1993).

A concentração populacional e a ação dos diversos agentes produtores do espaço propiciaram a expansão dos tecidos urbanos, favorecendo os processos de conurbação (TESSARI, 2009).

No Brasil, até o presente momento são poucos os estudos que tratam da expansão periférica em conurbações de cidades médias não metropolitanas; entre eles encontram-se os de Tessari (2009), Ströher (2011) e Polidoro (2012).

Esse trabalho aborda o fenômeno da expansão urbana, o crescimento horizontal que acontece nas bordas da cidade. Seu objetivo consiste em investigar a expansão e a produção do espaço periférico que ocorreu na conurbação Pelotas-Capão do Leão, R.S. no período de 1990 a 2011. A análise foi realizada a partir de técnicas de Sensoriamento Remoto que utilizaram imagens LANDSAT 5 do Sensor ThematicMapper (TM). Os dados foram processados nos softwares Spring e Arc GIS. Além desse procedimento foram realizadas entrevistas nas prefeituras, pesquisa bibliográfica e IBGE. Na sua elaboração partiu-se da premissa de que a expansão em um fenômeno urbano conturbado, não pode ser entendida sem incorporar a conurbação como um todo e sua articulação no âmbito microrregional e regional imediato. Sua importância está em poder vir a servir de base para planejamento e gestão urbana. Dessa forma está estruturado em três seções além da introdução e considerações finais. A primeira; aborda aspectos teóricos referentes à periferia; a segunda; a metodologia utilizada e a terceira; resultados e discussão. 


\section{A periferia urbana}

Embora se associe a primeira revolução industrial ao processo de suburbanização ele consiste em um fenômeno anterior. Munford (1998) comenta que foram encontrados restos de núcleos suburbanos fora da área construída da cidade de Ur, e também na cidade egípcia, que apresentava subúrbios com espaçosos jardins. Já na alta idade média, de acordo com Benevolo (2015) e Munford (1998), o centro era o lugar das classes abastadas e a periferia, fora dos muros, dos pobres.

Segundo Munford (1998) "o fato de que o subúrbio se torne visível quase tão cedo quanto a própria cidade, talvez explique a capacidade de sobrevivência da cidade antiga frente a condições insalubres que predominavam dentro de seus muros."

Nesse sentido, a primeira revolução industrial, dos séculos XVIII e XIX também acarretou a formação de periferias. As pessoas que deixavam o campo e se dirigiam às cidades localizavam-se em bairros específicos já constituídos, mas também formavam aglomerações no seu entorno, nas imediações das indústrias. Nas cidades inglesas, nesse período inicia-se uma nova espacialidade. A população de alto padrão se dirige aos subúrbios amenos, distinto da época pré-industrial, centro- periferia (ENGELS,1975).

Nesse período observaram-se nas áreas urbanas, transformações tanto quantitativas quanto qualitativas. Quantitativas ao proporcionar em poucas décadas aumento, tanto do contingente populacional quanto de sua extensão, e qualitativas; pelo fato de ter gerado uma nova forma urbana, constituída não só pela cidade consolidada em si, mas por uma área localizada entre o centro urbano e a área rural circundante; a periferia (CHOAY, 1962; CERASI 1972).

Os subúrbios, principalmente os constituídos entre 1850 e 1920 devem sua existência à estrada de ferro e, a partir de 1895, ao bonde e ao metrô. Esses locais que cresciam junto às estações possuíam características de unidades de vizinhança, onde os percursos eram realizados a pé.

Nessa mesma época, no Brasil, (fins do século XIX e início do XX) foram realizadas em diversas cidades, reformas urbanas centradas em obras de saneamento básico e embelezamento paisagístico atreladas aos interesses do mercado imobiliário expulsando os moradores com menores recursos das áreas centrais para os morros e periferia. Maricatto (2000) exemplifica o fato com as cidades do Rio de Janeiro, Porto Alegre, Belém, Santos, Recife, São Paulo e Curitiba. Nesse contexto, Villaça (2001) afirma que foi na passagem do século que surgiu o subúrbio ou periferia, pobre e subequipada, como forma de inserção no espaço urbano típica das camadas de mais baixa renda.

Logo que o automóvel se tornou comum, nos anos 1920 e 1930 a fuga para o exterior da cidade se transformou num movimento de massa. Nos Estados Unidos, a vida em bairros jardins longe dos centros urbanos, ganha destaque. 
Segundo Munford (1998) o subúrbio se tornou visível no século XX no movimento coletivo em direção às áreas suburbanas. A partir desse período produziu-se uma nova espécie de comunidade que constituía uma caricatura da cidade histórica: uma multidão de casas uniformes identificadas alinhadas de maneira inflexível a distâncias uniformes, em estradas uniformes num deserto desprovido de árvores habitado por pessoas de mesma idade e renda.

Nas cidades latino americanas, da cidade colonial até os anos 1970, os grupos sociais de maior renda residiam nas áreas próximas ao centro e os pobres nas periferias. As indústrias por sua vez, se situavam sobre os eixos de transportes que ligavam o centro as periferias (CLINCHEVSKY,2000).

A partir desse período a forma urbana se torna mais complexa, ultrapassa os limites da aglomeração seguindo os ditames do capital e trabalho garantindo assim a sua reprodução. De acordo com Clichevsky (2000),

La ciudad posee una configuración territorial más compleja que en décadas anteriores y los agentes que la producen son múltiples, perteneciendo a los sectores más polarizados de la sociedad, pudiendo identificarse desde las grandes corporaciones internacionales que comienzan a actuar, fundamentalmente, en los años ochenta y acentúan sus inversiones en la década del noventa, a los agentes "informales" y la población que ocupa tierra y construye su propio hábitat de innumerables formas (CLINCHEVSKY,2000).

Correa (1989) salienta que a periferia urbana no Brasil tem sido objeto de práticas territoriais das classes dominantes;

Práticas que se traduzem em práticas complementares em relação às outras partes do território nacional. Estas práticas na periferia urbana estão inseridas, de um lado, no processo de acumulação de capital, seja através da incorporação e produção imobiliária, seja através da extração de urna renda fundiária, seja através da utilização de terrenos baratos para implantação industrial e de serviços diversos. De outro, se insere no processo de controle social através da reprodução segregada das diferentes classes sociais e suas frações. Ambos os aspectos, acumulação e reprodução, são interdependentes (CORREA, 1989).

Assim, essas periferias são locais de reprodução das classes sócias que nelas habitam Carlos, (2008). A periferia de hoje, consiste em um local de transformação do espaço rural para urbano, o local da produção do espaço pela classe dominante através de práticas relativas à acumulação do capital HARVEY (1985), mas também das classes menos favorecidas (SANTOS,1981; KOWARICK,2000; SPOSITO,2004). 


\section{Materiais e métodos}

\section{A conurbação Pelotas Capão do Leão}

O termo conurbação foi aplicado por Patrick Geddes, no início do século XX, no intuito de explicar o processo em que diferentes núcleos urbanos se fundem até formarem uma aglomeração maior, porém, cada um desses núcleos possui seu próprio centro, sua própria estruturação (GEDDES,1994).

Villaça (2001, p.51) comenta que

o entendimento conceitual da conurbação deve-se pautar nos intercâmbios que são produzidos tanto quanto a cidade que absorve, quanto a cidade que é absorvida, ou seja, o processo conurbação ocorre quando uma cidade passa a absorver os núcleos urbanos localizados à sua volta, pertençam eles ou não a outro municípios. Assim uma cidade absorve a outra quando passa a desenvolver com ela uma 'intensa vinculação socioeconômica'.(VILLAÇA,2001p.51).

O autor analisa a conurbação a partir da expansão dos núcleos urbanos e das contradições existentes entre o crescimento físico e os limites administrativos municipais. Assim, são identificadas por ele quatro formas principais pelas quais as cidades em crescimento incorporam ou geram núcleos urbanos em seu entorno 1) a constituída por núcleos que nunca chegaram a atingir a condição de cidade, pois já nasceram com características de subúrbio; 2) aquela na qual a área central da cidade absorvida é frágil distante ou inexistente formando-se ou consolidando-se posteriormente; 3) a constituída por aglomerações que chegaram a se desenvolver enquanto cidades de uma maneira típica: a partir da expansão e diversificação de um núcleo central de serviços; 4) a formada por núcleos muito pequenos originados do período colonial os quais foram perdendo importância ao longo do tempo pois permaneceram a margem da cidade maior.

A conurbação Pelotas- Capão do Leão localiza-se na zona sul do estado do Rio Grande do Sul (ver Figura 01). Faz parte da Aglomeração Urbana do Sul, originalmente chamada Aglomeração Urbana de Pelotas, formada pelos municípios de Pelotas e Capão do Leão, conforme lei complementar n 9184 de 26 de dezembro de 1990. Através da lei complementar $n^{\circ} 11876$ de 26 de dezembro de 2002, a aglomeração recebeu sua atual denominação. Pela mesma lei passaram a fazer parte também os municípios de Rio Grande, Arroio do Padre e São José do Norte.

Segundo o censo do IBGE , 2010 a população urbana de Pelotas é de 306193 habitantes seu IDHM 0,739, já Capão do Leão conta com 22382 habitantes e IDHM 0,637 . 

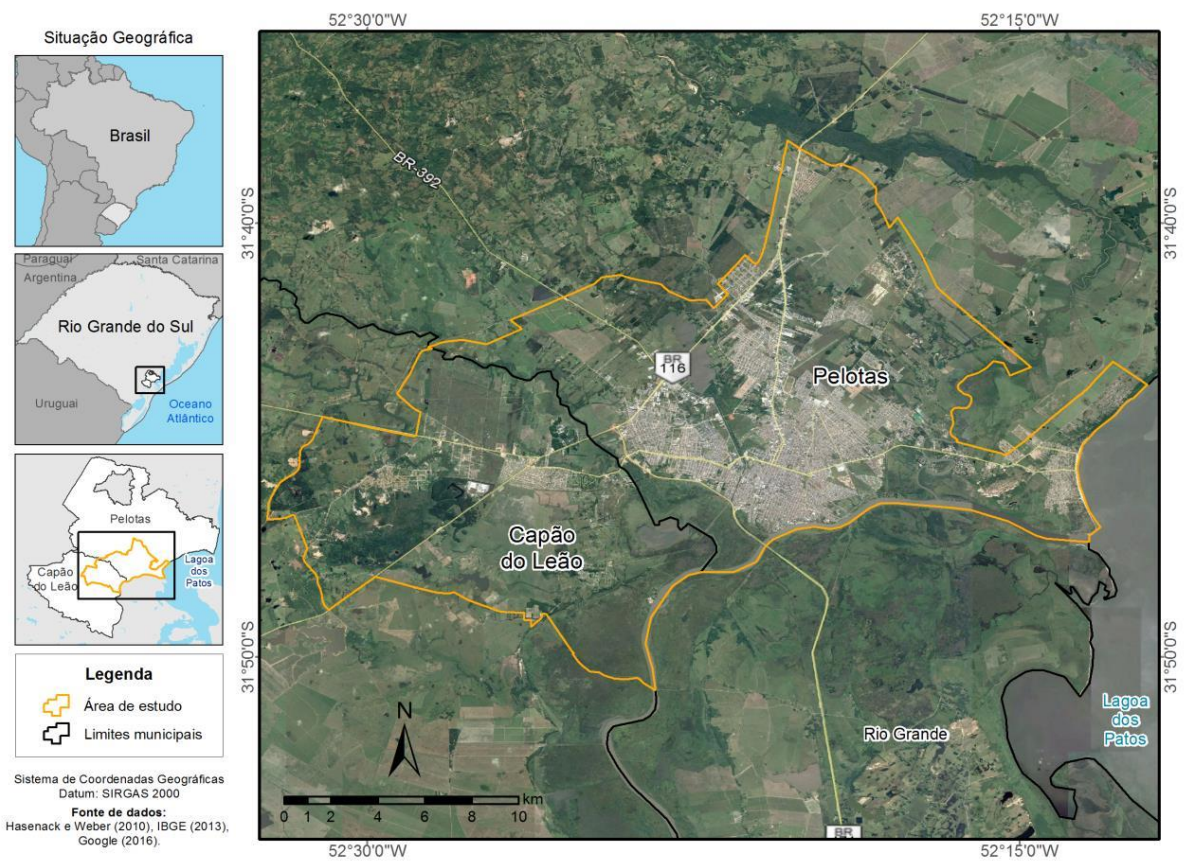

Figura 01: Conurbação Pelotas- Capão do Leão Elaboração própria a partir de imagem Google Earth ${ }^{\circledR}$

Atualmente Pelotas consiste no polo comercial e de serviços da região sul do R.S. Possui importante setor agroalimentar (beneficiamento de arroz, frigoríficos, indústrias de conservas) e também importante patrimônio arquitetônico cultural de forte influencia europeia sendo um dos maiores de estilo eclético do Brasil. A cidade se insere na Metade Sul do Rio Grande do Sul, região menos desenvolvida, do estado, no entanto apesar de apresentar relativa "estagnação econômica" continua exercendo importante papel de polo econômico e de atração de fluxos migratórios de centros urbanos menores, das zonas rurais do seu entorno e de outras partes do Brasil, esses últimos principalmente universitários (SOARES, 2005). Além desses, no período, pessoas que vieram buscar vagas no polo naval estabelecido em Rio Grande.

Contudo, apesar "crise econômica", que vive, Pelotas continua espacialmente apresentando crescimento tanto em seu núcleo central como expansão periférica.

Já o município de Capão do Leão foi emancipado de Pelotas em 3 de maio de 1982, através da Lei $\mathrm{n}^{\circ} 7647$, antes da cidade ser conhecida como Capão do Leão possuiu outras denominações, tais como: Serro, Santa Ana e Pavão (IBGE,2018).

Mais ou menos 1880 até a década de 1950, Capão do Leão converteu-se em local de veraneio das elites pelotense e riograndina. Essas pessoas foram atraídas pela 
beleza do lugar, fato que pode ser constatado através da arquitetura de algumas residências localizadas na Av. Narciso Silva e no bairro Theodósio

Quanto à produção do espaço deve-se considerar relevante também o fato de que em 1955 a Comercial \& Construtora América, que havia realizado a ampliação do bairro Jardim Europa, solicitou autorização à Prefeitura Municipal de Pelotas para o loteamento do bairro Jardim América, no então distrito do Capão do Leão. O bairro foi construído e por suas dimensões, com 94 ruas e 134 quadras sendo importante fator de urbanização local que ampliou e modificou significativamente a área urbana do município, dividindo-o em dois núcleos (SOARES,2005).

Atualmente a base da economia municipal é a agricultura seguida do extrativismo mineral, comércio e indústrias de pequeno, médio e grande porte, e também a prestação de serviços (IBGE,2019). Constitui a cidade satélite da conurbação.

\section{Aspectos metodológicos da pesquisa}

Para atingir o objetivo geral, a pesquisa em questão utilizou seis procedimentos metodológicos: 1) revisão bibliográfica; 2) entrevistas nas prefeituras de Pelotas e Capão do Leão com o objetivo de obter dados sobre a população e produção do espaço urbano no período de 1990-2011; 3) pesquisa de dados secundários, relativos à população das cidades no IBGE ( censos dos períodos 1990; 2000; 2010 ) no intuito de identificar o seu crescimento; 4) produção de mapas a partir de imagens de satélite de 4 períodos distintos de 1990 a 2011 para a identificação e quantificação da expansão das cidades 4) confrontação dos dados obtidos nos mapas com as imagens do Google Earth $^{\odot}$ de 2011 5) visita a campo nos locais de expansão 6) análise de dados.

\section{Sistema de Informação Geográfica e análise multitemporal por meio de imagens orbitais}

Uma das ferramentas que auxilia o manuseio e processamento de informações georreferenciadas são os sistemas de informações geográficas (SIG), compostos por hardwares, softwares e artifícios computacionais que possibilitam a análise espacial, gestão e representação do espaço físico, de fenômenos que nele ocorrem, com a finalidade de coordenar e organizar estes fenômenos através de mapas. No contexto se insere o sensoriamento remoto que permite o registro histórico e estudo do meio físico com a ajuda de imagens aéreas ou orbitais (MORAES, 2002).

A maioria das pesquisas focadas para estudos de expansão urbana que consideram técnicas de sensoriamento remoto possuem como principal objetivo a discriminação de áreas urbanas e não urbanas (HAMBURGER; VIEIRA, 2014). No comportamento espectral dos alvos urbanos, não é possível eleger um padrão, pois existem vários tipos de materiais associados (asfalto, concreto, telhas...) conforme relatado por Souza (2012). Esse autor também destaca que imagens com resolução 
espacial média (10-50 m) apresentam refletância intensa para manchas urbanas, na faixa do visível, sendo relativamente fácil a discriminação de outras coberturas terrestres. As informações sobre as características espectrais da paisagem urbana são limitadas, pois a maioria dos estudos são intra-urbanos. Os recursos mais utilizados são fotografias aéreas, que possuem alta resolução espacial (HAMBURGER; VIEIRA, 2014).

Aos efeitos de interpretar os motivos do crescimento, se analisaram parâmetros socioeconômicos (população) (IBGE, 2014), que foram ajustados por interpolação linear, às datas de interesse.

Para o estudo, foram utilizadas imagens do sensor ThematicMapper (TM), a bordo do satélite LANDSAT 5, correspondentes aos anos de 1990, 1996, 2001, 2006 e 2011; que foram conferidas com imagens de alta resolução disponíveis na mídia digital (Google Earth ${ }^{\odot}$ ). A melhor composição para discriminar o alvo pretendido (área urbana) foi a 345 em RGB, devido a maior variabilidade de tons, texturas e boa discriminação das outras coberturas do solo (SOUZA, 2012; HAMBURGER; VIEIRA, 2014).

As áreas urbanas foram digitalizadas como polígonos no programa SPRING 5.2.6, para evitar erros de inclusão e omissão, frequentes nos classificadores automáticos (D’ ARCO,2007). Os polígonos de cada área urbana foram organizados por ano, sendo sobrepostos em diferentes cores, para aprimorar a visualização do crescimento urbano, via o software ArcGis 9.3 (ESRI, 2014).Após a avaliação de áreas, os valores obtidos foram comparados com os dados dos Censos disponíveis nos anos 1991, 2000 e 2010 (IBGE, 2014), sendo interpolados linearmente os valores para os anos de interesse, de maneira a ter coincidência com as datas das imagens.

Quando a vetorização das imagens LANDSAT 5 foi confrontada com as imagens de alta resolução Google Earth®, identificou-se confusão nas regiões com ocorrência acentuada de areia, devido à resposta espectral semelhante com a área urbana.

Os períodos foram estabelecidos da seguinte maneira: para dados dos Censos, o primeiro período corresponde ao intervalo entre 1991 e 2000 e o segundo período ao intervalo entre 2000 e 2010; para os resultados das manchas urbanas, o primeiro período equivale ao intervalo entre 1990 e 2001, e o segundo período ao intervalo entre 2001 e 2011.

\section{Resultados e discussão}

\section{Crescimento de Pelotas e Capão do Leão 1990-2011: população e expansão urbana}

No período de 1991 a 2011, de acordo com a Tabela 01, Pelotas apresentou um aumento de 41.001 habitantes, ou 13,4\% e Capão do Leão 6.188 habitantes, 27,6\%.

Já a partir da Tabela 02 se pode verificar o expressivo aumento da área urbana tanto no caso de Pelotas 20,3km2 quanto Capão do Leão 16,4km2. Em Pelotas a ocupação ocorreu de acordo dados de entrevista realizada junto à secretaria de 
Planejamento Urbano da prefeitura municipal, e por análise de imagens do Google Earth®, através de assentamentos precários localizados na periferia a norte e oeste que apresentam (vias sem pavimentação, problemas de drenagem, valetas a céu aberto, ausência de áreas verdes e rede de esgotos), bem como, loteamentos e condomínios fechados de classe média e média alta no eixo leste rumo a Lagoa dos Patos (AUTOR, 2016). Dessa forma pode-se verificar um aumento populacional e de expansão da área urbanizada proporcional muito maior em Capão do Leão, o que pode ser explicado principalmente pelo menor preço da terra urbana periférica.

Em Pelotas de 1990 a 2011 observa-se o crescimento nas bordas da cidade, bem como o processo especulativo da criação de vazios urbanos (Figura 02). A expansão acontece seguindo as vias de transporte Villaça (2001) principalmente nas direções norte, oeste e leste, pois a sul tem-se o canal São Gonçalo ver Figura 02

No Capão do Leão de acordo com resultados de entrevista realizada junto à Secretaria Municipal de Obras Urbanismo e Meio Ambiente local observou-se principalmente a ocupação através de invasões do loteamento Parque Fragata em 2011, parcelamento datado dos anos 1950 (chácaras de lazer), com grande número de lotes vagos e a periferia do loteamento Jardim América. Observa-se também a partir dos dados, expressiva expansão em Capão do Leão de 1996 a 2011.

Ressalta-se que Capão do Leão é uma cidade dormitório. Cano (1988) relaciona a origem das cidades-dormitório ao processo de urbanização. Conforme OJima (2010) uma cidade dormitório é aquela cidade cujos habitantes saem na maioria, para trabalhar em outra cidade, no caso Pelotas voltando apenas para dormir, sendo, portanto, a mobilidade pendular um elemento característico também importante para o melhor entendimento do objeto de estudo. Em geral, essa terminologia costuma ser relacionada a algumas características, como no caso estudado, com o baixo dinamismo econômico, elevado crescimento populacional (JARDIM; BARCELLOS, 2004) e expansão urbana em assentamentos precários de população de baixa renda (CAIADO, 2005).

Tabela 01:População urbana (hab.) Pelotas e Capão do Leão 1991/2000/2011

\begin{tabular}{c|c|c}
\hline Item & Pelotas & Capão do Leão \\
\hline $\mathbf{1 9 9 1}$ & 265192 & 16194 \\
\hline $\mathbf{2 0 0 0}$ & 301081 & 21354 \\
\hline $\mathbf{2 0 1 0}$ & 306193 & 22382 \\
\hline
\end{tabular}

Fonte: Censo IBGE

Tabela 02:Expansão da área urbanizada $\left(\mathrm{Km}^{2}\right)$ Pelotas e Capão do Leão nos períodos

\begin{tabular}{c|c|c}
\hline Item & Pelotas & Capão do Leão \\
\hline $\mathbf{1 9 9 0 - 1 9 9 6}$ & 5,8 & 2,3 \\
\hline $\mathbf{1 9 9 6 - 2 0 0 1}$ & 2,5 & 2,8 \\
\hline $\mathbf{2 0 0 1 - 2 0 0 6}$ & 4,0 & 3,5 \\
\hline $\mathbf{2 0 0 6 - 2 0 1 1}$ & 8 & 7,9 \\
\hline
\end{tabular}

Fonte: Elaboração própria 
O relatado acima pode ser em parte explicado em termos regionais pelo fato da instalação de um polo naval na vizinha cidade de Rio Grande que demandou de acordo com Domingues (2008), Feijó (2012) expressiva mão de obra. É importante relatar também, que no período houve uma supervalorização dos imóveis na cidade de Rio Grande o que veio a refletir no mercado imobiliário de Pelotas. Assim conforme Silva (2012)

Com mais de 10 bilhões de reais em investimentos, o Polo Naval do Rio Grande vem, a partir de 2006, atraindo um grande número de trabalhadores de outras regiões do Brasil. Esse fluxo migratório ocasionou um aumento na demanda por imóveis que associado à baixa oferta disponível causou um impacto nos preços, tanto para locação como para venda (SILVA, 2012).

Outro fato relevante que pode ser observado consiste na ocupação de áreas parceladas dentro do perímetro urbano das duas cidades o que significa que as regulamentações urbanísticas, as leis de Uso e Ocupação do Solo de Planos diretores estão sendo seguidas (ver Figura 01)

Salienta-se que as duas cidades tiveram maior expansão da área urbanizada no período de 2006 a 2011; $8 \mathrm{Km} 2$ em Pelotas e 7,9 Km2 no Capão do Leão, que correspondeu ao auge do funcionamento do polo naval.

Por fim, cabe ressaltar que a população vem a ocupar os lugares disponíveis; não necessariamente os mais distantes do centro da cidade na evolução do tempo (ver figuras 02 e 03)

Pela análise dos mapas, figuras 02 e 03 e a partir das entrevistas pode-se identificar a formação de vazios urbanos no processo de produção do espaço. Segundo Arendit (1993) o vazio urbano consiste em uma estratégia de especulação dos proprietários de terras urbanas aliados à necessidade de estocagem de terra por parte dos capitais ligados a produção imobiliária no intuito de criar uma valorização de áreas urbanas que se tornam inacessíveis a grande parte da população.

Por fim, verifica-se também a fragmentação e difusão dos espaços de ambas as cidades Santos (1993), que vem a apresentar uma configuração cada vez mais complexa (CLINCHEVSKY, 2000). Assim, a periferização se acentuou na medida em que houve um aumento da especulação imobiliária e do custo de vida. 


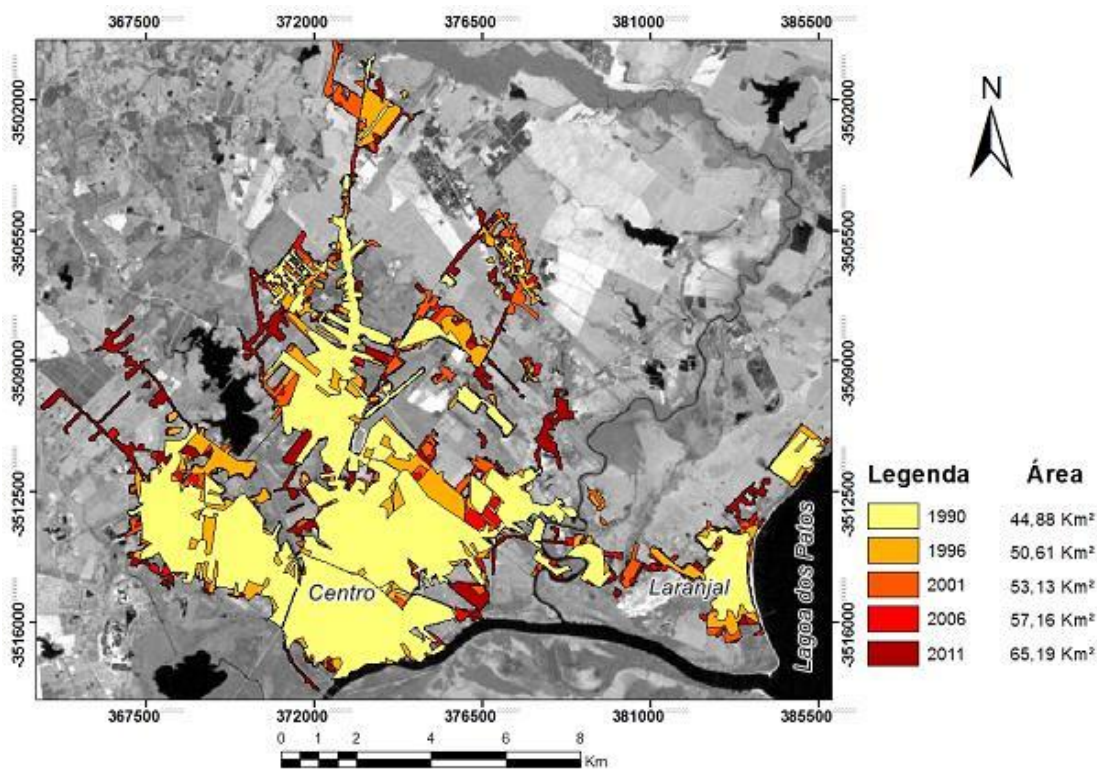

Figura 02: Mapa resultante da vetorização do município de Pelotas, sobreposta a uma imagem do sensor TM pertencente ao satélite LANDSAT 5.

Fonte: Org. GALLO, B. B., 2014.

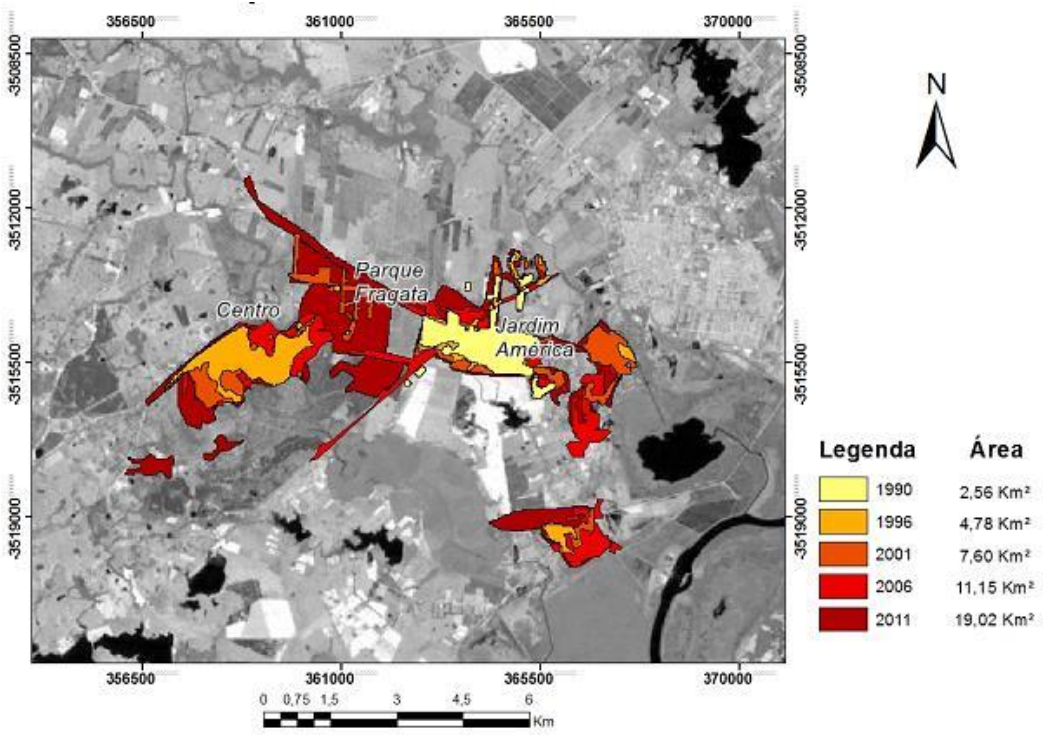

Figura 03: Mapa resultante da vetorização do município de Capão do Leão, sobreposta a uma imagem do sensor TM pertencente ao satélite LANDSAT 5.

Fonte: Org. GALLO, B. B., 2014. 


\section{A evolução da Periferia na conurbação pelotas Capão do Leão}

A cidade de Pelotas apresenta três vetores principais de crescimento urbano; o setor Norte, o Leste e o Oeste. Ao sul não há possibilidade de expansão, na medida em que se localiza ali, o Canal São Gonçalo. Já Capão do Leão apresenta dois vetores opostos em direção ao centro da cidade a oeste e em direção a Pelotas a leste. ver Figura 04.

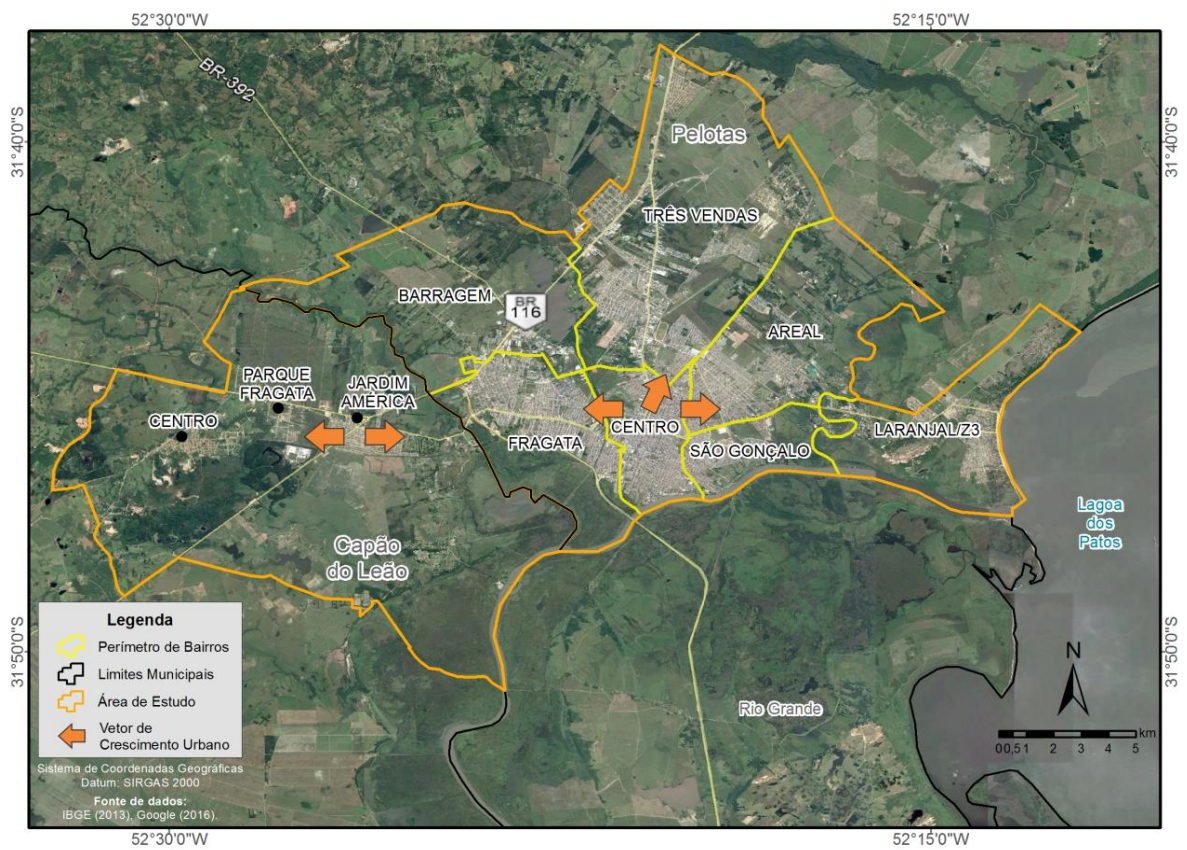

Figura 04: Vetores do crescimento Pelotas e Capão do Leão

Fonte: Elaboração própria

Em Pelotas, o setor Norte desenvolve-se em três áreas; A primeira denominada "zona norte" onde são construídos empreendimentos de alto padrão, principalmente apartamentos. A segunda, formada por assentamentos populares, conjuntos habitacionais promovidos pelo Estado, e loteamentos populares. E a terceira, constituída pelo eixo principal a Av. Fernando Osório onde se localizam atividades atacadistas, transportadoras e indústrias (SOARES,2005). A leste, a área expande-se em direção ao Laranjal, balneário localizado ha $12 \mathrm{Km}$ do centro da cidade e de uma Zona de Preservação Ambiental estabelecida no primeiro e segundo Plano Diretor de Pelotas, respectivamente Lei 2565/1980 e Lei 5502/2008. Os atrativos do sítio foram os motores do crescimento (a orla da Lagoa dos Patos, dunas e área de mata) Autor (2016) e Villaça (2001p.107) que assim comenta: 


\begin{abstract}
Embora de enorme importância na determinação espacial da expansão urbana, as vias regionais de transporte não são a única força nessa determinação. Mesmo desempenhando eventualmente um papel demográfica e territorialmente secundário, os atrativos do sítio natural têm constituído importante fator de atração da expansão urbana (VILLAÇA, 2001 p.107).
\end{abstract}

Esse setor está ligado de maneira específica com os estratos de maior renda na constituição de empreendimentos de alto padrão, loteamentos e condomínios fechados em um processo de auto segregação (SPOSITO 2013a, 2013b).Essa periferia segundo Correa (1989) constitui-se na periferia litorânea local que apresenta características naturais, como amenidades microclimáticas e beleza natural, e social. Nesse caso é importante fazer referencia que o meio de transporte utilizado pelos ocupantes desses loteamentos é basicamente o automóvel particular. Reitera-se aqui o interesse das classes de maior poder aquisitivo de ocupar esses espaços desde tempos mais remotos Benevolo (2015), Engels (1975) e no caso mais atual, Munford (1998) nas cidades norte americanas.

Já no eixo Oeste conformado pelo bairro Fragata, (denominado bairro Operário) e eixo da conurbação, o tecido urbano expande-se em direção ao município do Capão do Leão, fato que teve início nos anos 1970 quando houve a ocupação do bairro Jardim América e parque Fragata com mais de 1.000 lotes populares (SOARES, 2005).

No caso estudado, a conurbação Pelotas- Capão do Leão, o início da absorção do núcleo urbano do Capão do Leão por Pelotas ocorreu partir de 1950, com a construção dos Loteamentos Jardim América, e Parque Fragata (pertencentes nessa época a Pelotas) e localizados próximos ao Teodósio, (primeiro núcleo da povoação) local onde existia uma antiga estação ferroviária. No entanto Capão do Leão consolidase nos anos 1970 .

Assim de acordo com Soares (2005)

Nos anos 70, quando o município ainda era um distrito de Pelotas, ocorreu a ocupação dos loteamentos Jardim América e Parque Fragata, ambos com mais de 1.000 lotes populares. Em 1982, ao emancipar-se o Capão do Leão, estes loteamentos constituíram os "bairros" do novo município (SOARES 2005).

É importante ressaltar, que o Jardim América pode ser definido como uma prolongação do bairro Fragata (vetor oeste de crescimento de Pelotas) funcionando como um grande atrator em direção a referida povoação. Deve-se fazer referencia também, que o Bairro Fragata apresenta características peculiares por constituir o eixo de conurbação do tecido urbano da cidade de Pelotas que se "espraia" sobre o espaço municipal de Capão do Leão. O crescimento periférico neste vetor ocasionou o "transbordamento" (Villaça, 2001) da mancha urbana da cidade de Pelotas, dando origem a conurbação atual. 
Além do exposto, cabe salientar a importância dada às vias regionais de circulação para a consolidação e formação da conurbação. Na conurbação PelotasCapão do Leão os deslocamentos produzidos no vetor oeste efetivaram uma integração regional periférica, materializada, fundamentalmente, pelas vias regionais de circulação. Assim, a interação de funções urbanas, bem como ações complementares de integração socioeconômica, o movimento e os fluxos de pessoas, veículos, mercadorias e serviços, proporcionam articulação entre ambos os núcleos urbanos formando a conurbação.

Já o caso a expansão do Capão do Leão pode ser analisada nos seguintes termos: observa-se que embora o primeiro núcleo, tenha sido o centro, Teodósio (em laranja no mapa à esquerda) (Figura 04) ele efetivamente foi ocupado em 1996. Já o loteamento Jardim América, que pertencia a Pelotas antes da emancipação do município do Capão do Leão, (em amarelo no mapa) (Figura 04) já era ocupado anteriormente a 1990.

Quanto ao Parque Fragata, loteamento conformado por chácaras de lazer com lotes de 15x150 implantado em 1953, começou a ser ocupado em 1970 e, a partir de 2011 teve sua ocupação de modo irregular, principalmente por pessoas provenientes de municípios da região, como Pelotas, Piratini, Canguçu etc. O crescimento da área urbana tanto em população como em extensão deve-se ao fato principalmente de o solo urbano ter menor valor na cidade de Capão do Leão, do que na cidade polo da aglomeração; Pelotas e também por estar próximo ao distrito industrial dessa cidade.

A periferização dos assentamentos e a especulação imobiliária teriam provocado importantes mudanças no processo de urbanização no caso da conurbação estudada fazendo surgir aí a "cidade-dormitório" de Capão do Leão.

Assim, os interesses fundiários e imobiliários foram motores principais da expansão das cidades, (SPOSITO, 2004; HARVEY ,1985, 1990). A produção do espaço urbano foi direcionada principalmente através implantação de loteamentos, no Capão do Leão, (vetor oeste), Jardim América nos anos 1970. Já no vetor leste em Pelotas, pelos dos balneários Santo Antônio e Valverde na mesma época, e atualmente através de loteamentos e condomínios fechados ou pelo contínuo lançamento de novos produtos imobiliários de forma a buscar novos mercados consumidores. Essa lógica tem levado o espaço urbano no vetor leste a crescer mais territorialmente do que demograficamente.

Nesse sentido, o Capão do Leão consiste na cidade satélite de Pelotas, mas também periferia deste; periferia ocupada por pessoas de menor poder aquisitivo; segundo Correa (1989) a periferia interiorana, a periferia no caso específico ônibus interurbano e horas desperdiçadas no transporte, da autoconstrução e do sobre trabalho, das favelas da falta de esgotos e de vias calçadas, que se beneficiam pelo fato de a terra urbana ali ser mais barata ou até gratuita no caso das ocupações em áreas públicas, praças e áreas institucionais no loteamento Jardim América e Parque Fragata. A atual ocupação habitacional corresponde a uma produção, resultado de migrações de populações pobres provenientes de Pelotas ou municípios da zona sul do Rio Grande do Sul sem acesso a moradia. 


\section{Considerações finais}

O crescimento da população urbana, durante o período 1990-2011 na conurbação Pelotas-Capão do Leão tem sido acompanhado por um aumento na demanda por áreas urbanas, fato que proporcionou a ocupação de suas áreas periféricas. Observase dois tipos de periferias, a periferia litorânea e a interiorana Correa (1989) com seus processos de segregação e autosegregação no primeiro caso, e segregação em si no segundo. Observa-se em Pelotas e Capão do Leão a periferia interiorana conformada por assentamentos com problemas relacionados à infraestrutura e serviços urbanos, enquanto que a periferia denominada litorânea, que não apresenta esses tipos de problemas é observada apenas em Pelotas, cidade principal da conurbação.

A análise das imagens de ambas as cidades configura no período estudado, um espaço fragmentado e difuso, principalmente na periferia, embora este se localize dentro dos perímetros urbanos seguindo as regulamentações locais. Deve-se fazer referencia também que a taxa de crescimento tanto populacional quanto de expansão de Capão do Leão ser maior que a de Pelotas no período.

Assim a periferização dos assentamentos humanos e a especulação imobiliária teriam provocado importantes mudanças no processo de urbanização como a formação da conurbação e a consequentemente fazendo surgir aí a "cidade-dormitório", Capão do Leão.

Nesse sentido, verificam-se dois movimentos de população 1) migração de população da zona rural, ou de outras localidades para Pelotas em busca de novas oportunidades de trabalho (principalmente a implantação de um polo naval na cidade vizinha de Rio Grande) ;2) a supervalorização da terra urbana direciona essa população para Capão do Leão que permanece com seus postos de trabalho em Pelotas.

Para concluir a expansão na conurbação revela a expansão das desigualdades e a exclusão social conformada na periferização que se acentuou na medida em que houve um aumento da especulação imobiliária.

\section{Referencias}

ARENDIT, E.J. Expansão urbana em Campinas: Ocupação do solo, consequências sociais e atuação do poder público municipal. 1993. 183f. Dissertação (Mestrado em Ciências Sociais),PUC-São Paulo, 1993.

BENEVOlO, L. História da cidade. São Paulo: Perspectiva Brasil, 2015.

BRASIL,Lei Federal n. ${ }^{\circ}$ 6.766, de 19 de dezembro de 1979. Dispõe sobre o parcelamento do solo urbano.Disponível em:

<http://www.planalto.gov.br/ccivil_03/LEIS/L6766.htm> Acesso em 26 de maio de 2018.

CARLOS, A. F. A (re) produção do espaço urbano. São Paulo: EDIUSP,2008.@ 
CAIADO, M. C. S. Estruturação intra-urbana na região do Distrito Federal e entorno: a mobilidade e a segregação socioespacial da população. Revista Brasileira de Estudos Populacionais, v.22, n.1, p.55-88, jan/jun. 2005.

CANO, W. Questão regional e urbanização no desenvolvimento econômico brasileiro pós 1930. In: ENCONTRO NACIONAL DE ESTUDOS POPULACIONAIS, 6., 1988, Olinda. Anais... Olinda, Abep, 1988, p. 67-99.

CARVALHO,E. exclusão social e crescimento das cidades médias brasileiras. Scipta Nova. v.VII, n.146,2003.

CHOAY, F. Urbanismo: Utopías y realidades. São Paulo: Perspectiva, 2015.

CERASSI, M. Citta i periferia: condizioni e tipi della residenzia delle classi subalterne della citta moderna. Milano:Cooperativa Libraria Universitaria del Politecnico,1973.

CORRÊA, Roberto Lobato. A periferia urbana. Geosul, n.2, 2º sem. 1989.

CLICHEVSK, N. Informalidad y segregación urbana em América Latina. una aproximación.Santiago: CEPAL Medio ambiente y desarrollo 2000.

DOMINGUES, M. V. D. L; CARVALHO, D. S; MENEZES, G. R. Polo Naval do Rio Grande: Primeiros insights sobre a formação de um cluster portuário marítimo. In: SEMINÁRIO INTERNACIONAL SOBRE DESENVOLVIMENTO REGIONAL, 4, 2008, Santa Cruz do Sul. Anais... Santa Cruz do Sul.2008,.p.367-376.

D`ARCO, E. O uso de geotecnologias para estimativas da área plantada de arroz irrigado no estado do Rio Grande do Sul. 2007. 209 f. (INPE-15326- TDI/1369). Tese (Doutorado em Sensoriamento Remoto) - Instituto Nacional de Pesquisas Espaciais, São José dos Campos. 2007.

ENGELS, F. A situação da classe trabalhadora na Inglaterra.Porto: Apontamentos, 1975 .

ESRI The Arc GIS Plataform Disponível em< https://www.esri.com/esrinews/arcnews/summer14articles/the-arcgis-platform-in-2014> acesso em 29 jun.2018.

FEIJÓ, F.T.; MADONO, D. T. Polo Naval do Rio Grande: potencialidades, fragilidades e a questão da migração. In: ENCONTRO DE ECONOMIA GAÚCHA, 6, 2012, Porto Alegre. Anais... Porto Alegre 2012, p.76-88.

GEDDES, P. Cidades em evolução. Tradução de Maria José Ferreira de Castilho. Campinas: Papirus, 1994. 274p.

HARVEY, D. The urbanization of capital. Oxford: Blackwells, 1985.

HARVEY, D. Los limites del capitalismo y de la teoria Marxista. México: Fondo de Cultura econômica, 1990.

HAMBURGER, D. S.; VIERA, I. M. Estudo do comportamento espectral de alvos urbanos para discriminação de áreas residenciais. São José dos Campos. Instituto 
Nacional de Pesquisas Espaciais, INPE. (s.d.) Disponível em:<http://www.inpe.br/> Acesso em 28 jun. 2018.

IBGE Censos Demográficos, 2014 Disponível em

<https://ww2.ibge.gov.br/home/estatistica/populacao/censodem/default_censo1991.shtm $>$ acesso em 29 jun2018.

IBGE Cidades.Disponível em< https://cidades.ibge.gov.br/> acesso em 20 de mai 2019.

IBGE Estimativas de população Disponível em< https://www.ibge.gov.br/estatisticasnovoportal/sociais/populacao/9103-estimativas-de-

populacao.html?=\&t=resultados2018> acesso em 21 fev 2019.

IBGE. Atlas do Desenvolvimento Humano no Brasil 2013. Disponível em: </>. Acesso em: http://atlasbrasil.org.br/2013/ Acesso em 20 mar. 2018.

JARDIM, M. de L.; BARCELLOS, T.M. de. Mobilidade populacional na RMPA nos anos 90. In: ENCONTRO NACIONAL DE ESTUDOS POPULACIONAIS, 14., Anais... Caxambu: Abep, 2004. (CD-ROM).

KOWARICK, L, Escritos urbanos. São Paulo, Brasil: Editora 34, 2000.

MARICATO, E. Urbanismo na periferia do mundo globalizado: metrópoles brasileiras. São Paulo em Perspectiva, São Paulo, v.14, n.4, p.21-33, out-dez. 2000.

MORAES, E. C. Fundamentos de sensoriamento remoto. São José dos Campos: Instituto Nacional de Pesquisas Espaciais, INPE, 2002

OJIMA, R. O estigma de morar longe da cidade: repensando o consenso sobre as “cidades-dormitório” no Brasil. Cadernos Metrópole.v.12,n.24,2010.

POLIDORO, M. Conurbação e dispersão em aglomerações urbanas: desafios ao planejamento. 2012, 205f. Dissertação (Programa de Pós-Graduação em Engenharia Urbana). Universidade Federal de São Carlos, UFSCAR. São Paulo, 2012.

PREFEITURA MUNICIPAL DE PELOTAS. Lei 2565 de 1980, Institui o segundo Plano Diretor.Disponível em:< https://leismunicipais.com.br/plano-diretor-pelotas-rs > Acesso em 27 de maio de 2018.

PREFEITURA MUNICIPAL DE PELOTAS Lei 5502 de 2008,Institui o Terceiro Plano Diretor.Disponível em:< https://leismunicipais.com.br/plano-diretor-pelotas-rs $>$ Acesso em 27 de maio de 2018.

RIO GRANDE DO SUL, Lei complementar $n^{\circ}$ 9184, de 26 de dezembro de 1990. Instituí a Aglomeração Urbana de Pelotas.Disponível em:

<https://sogi8.sogi.com.br/Arquivo/Modulo113.MRID109/Registro25925/documento\%2 01.pdf> acesso em 26 de maio de 2018.

RIO GRANDE DO SUL, lei complementar n 11876 de 26 de dezembro de 2002. Institui a Aglomeração Urbana do Sul. Disponível em: <http://leisestaduais.com.br/rs/ > Acesso em 26 de maio de 2018. 
RIO GRANDE DO SUL,Lei ordinária 7647 de 3 de maio de 1982 Cria o município de Capão do Leão.Disponível em:< http://leisestaduais.com.br/rs/ > Acesso em 26 de maio de 2018.

SANTOS, M. Manual de Geografia Urbana, São Paulo: Hucitec,1981.

SANTOS, M. Urbanização brasileira. São Paulo: Hucitec,1993.

SILVA, Rogério Piva da. et al. O impacto do Polo Naval no setor imobiliário da Cidade do Rio Grande/RS. In: $6^{\circ}$ ENCONTRO DE ECONOMIA GAÚCHA, 2012, Porto Alegre. Anais...Porto Alegre/RS, 2012. p.67 -77.

SOARES, P. R. Produção imobiliária e reestruturação urbana nas cidades de Pelotas e Rio Grande (RS). In: X ENCONTRO DE GEÓGRAFOS DA AMÉRICA LATINA, 2005. São Paulo. Anais... São Paulo, 2005.p.223-247

SOUZA, I. M. Sensoriamento remoto orbital aplicado a estudos urbanos. São José dos Campos, cap. 1. São José dos Campos. Instituto Nacional de Pesquisas Espaciais, INPE. 2012. Disponível em:< http://www.inpe.br/ >Acesso em 25 abril de 2018.

SPOSITO, M. E. B. Espaços residenciais fechados e cidades: insegurança urbana e fragmentação socioespacial. São Paulo:ed Unesp, 2013a.

SPOSITO, M. E. B. Segregação socioespacial e centralidade urbana. In:VASCONCELOS,P.de A. (Org) A cidade contemporânea: segregação espacial São Paulo: Contexto,2013b. p.79-91.

SPOSITO, M. E. B. Novos conteúdos nas periferias urbanas das cidades médias do estado de São Paulo. Investigaciones Geográficas, Boletín del Instituto de Geografia, n. 54, 2004.

SPOSITO, M. E. B. O chão em pedaços: urbanização, economia e cidades no Estado de São Paulo. Tese (Livre-Docência). Universidade Estadual Paulista, Faculdade de Ciências Tecnologia. Presidente Prudente: [s.n], 2004.

MUMFORD, L. A cidade na História, São Paulo: Martins Fontes,1998.

STRÖHER, L. E. M.; SOUZA, G. B. de. De vilarejo à cidade conurbada: a expansão de Sarandi condicionada pela ação de três agentes imobiliários e pelo parcelamento rural. Revista Tecnológica, Maringá, v. 20, p. 63-74, 2011.

VILLAÇA, F. O espaço intra-urbano no Brasil. São Paulo: Nobel, FAPESP, Lincoln Institute, 2001.

TESSARI, L.M. O processo de expansão urbana e conurbação em uma aglomeração urbana não metropolitana no interior paulista.2009,162f. (Dissertação Mestrado em Geografia).UNESP, Rio Claro S.P. 2009. 


\section{Claure Morrone Parfitt}

Arquiteta pela Universidade Federal de Pelotas; Mestre e Doutora em Planejamento Urbano e Regional pela Universidade Federal do Rio Grande do Sul. Atualmente é professora adjunta do Curso de Bacharelado em Gestão Ambiental do Centro de Integração do MERCOSUL, e do curso de Especialização em Gestão Pública e Desenvolvimento Regional ambos da Universidade Federal de Pelotas.

End: Rua Andrade Neves,1529- Pelotas,Rio Grande do Sul Brasil- CEP 96020-080 Fone (53) 99833933

E- mail: clauremparfitt@gmail.com

\section{Betty Braga Gallo}

Tecnóloga em Geoprocessamento Universidade Federal de Pelotas.

End, Rua Marechal Deodoro da Fonseca $n^{\circ}$ 884, Centro. Pelotas/RS. CEP: 96020-220. Fone (53) 8109-7620

E-mail: bettybraga@yahoo.com.br

José Maria Filippini Alba

Doutor em Geociencias pela Universidade de São Paulo; Pesquisador do Centro de Pesquisas de Clima Temperado - EMBRAPA-CPACT Pelotas, Brasil -End. Rodovia BR-392, Km 78, $9^{\circ}$ Distrito, Monte Bonito Caixa Postal 403, CEP: 96010-971 - Pelotas, Rio Grande do Sul Fone: (53) 32758229

E- mail: jose.filippini@gmail.com 